\title{
PENGGUNAAN MENYAN UNTUK MENINGKATKAN KETRAMPILAN BERBICARA DI SMP NEGERI 2 GENTENG KABUPATEN BANYUWANGI
}

\author{
Sapto Orbayani ${ }^{1}$ \\ ${ }^{1}$ SMP Negeri 2 Genteng, Banyuwangi
}

Received : June 14, 2020 Revised : June 16, $2020 \quad$ Accepted : June 18, 2020

\begin{abstract}
ABSTRAK
Penelitian bertujuan untuk meningkatkan hasil belajar siswa yang belum mencapai ketuntasan belajar minimal (KBM) melalui media nyanyian (MENYAN) pada keterampilan berbicara materi "What's your name" dan "Family member". Jenis penelitian ini termasuk penelitian tindakan kelas (PTK). Subjek penelitian adalah siswa kelas VIIA SMPN 2 Genteng kabupaten Banyuwangi sebanyak 34 siswa. Penelitian ini dilaksanakan dalam dua siklus. Pengumpulan data awal menggunakan kuesioner dan pretes. Pengambilan data diambil melalui tes dan obeservasi pada akhir siklus I dan akhir siklus II. Data yang terkumpul diolah menggunakan analisis kuantitatif. Hasil yang dicapai setelah penggunaan MENYAN terbukti dapat meningkatkan keberanian siswa dan hasil belajar siswa pada nilai. Pada siklus I (kuesioner) siswa yang berani berbicara 0 siswa (0\%), pada akhir siklus I terdapat 17 siswa (50\%) yang berani berbicara dan pada akhir siklus II terdapat 25 siswa $(73.53 \%)$ yang berani berbicara. Sedangkan yang mencapai KBM pada pra siklus I terdapat 11 siswa (32.5\%), siklus I terdapat 18 siswa (52.94\%), dan pada siklus II terdapat 27 siswa (79.41\%). Dengan demikian disarankan agar penggunaan MENYAN dapat diterapkan pada materi lain dengan mempertimbangkan karakteristik mata pelajaran dan karakteristik siswa.
\end{abstract}

Kata kunci: Berbicara, hasil belajar, MENYAN

\begin{abstract}
The research aims to improve the learning outcomes of students who have not yet reached the minimum learning completeness (KBM) through singing media (MENYAN) on the speaking skills of the material "What's your name" and "Family member". This type of research includes classroom action research (CAR). The subjects of the study were 34 students in class VIIA SMPN 2 Genteng, Banyuwangi district. This research was conducted in two cycles. Initial data collection using questionnaires and pre-tests. Data is collected through tests and observations at the end of the first cycle and the end of the second cycle. The data collected is processed using quantitative analysis. The results achieved after the use of MENYAN are proven to increase student courage and student learning outcomes on grades. In the first cycle (questionnaire) students who dared to speak 0 students (0\%), at the end of the first cycle there were 17 students (50\%) who dared to speak and at the end of the second cycle there were 25 students (73.53\%) who dared to speak. While those who reached KBM in the first cycle there were 11 students (32.5\%), in the first cycle there were 18 students (52.94\%), and in the second cycle there were 27 students (79.41\%). Thus it is recommended that the use of MENYAN can be
\end{abstract}


applied to other material by considering the characteristics of the subjects and the characteristics of students.

Keyword: Speaking, learning outcomes, MENYAN,

\section{PENDAHULUAN}

Keterampilan berbicara merupakan bagian penting dari sistem pembelajaran bahasa Inggris bagi penutur bahasa kedua. Pada sebagian orang, seseorang dikatakan bisa berbahasa Inggris manakala mampu menampilkan sebuah komunikasi yang nyata di hadapan publik padahal di negara penutur bahasa kedua hampir tidak bisa kita jumpai orang berbahasa Inggris setiap hari (Ismukoco, 2017).

Sebelum peneliti mengadakan PTK ini, peneliti telah melakukan jajak pengalaman melalui kuesioner yang diberikan kepada siswa kelas VIIA yang berjumlah 34 siswa. Laki-laki berjumlah 11 dan perempuan berjumlah 23. Berikut ini adalah hasil angket itu:

1. Siswa merasa bahwa kegiatan berbicara bahasa Inggris jarang dilakukan di dalam kelas. Mereka yang menyatakan demikian sebanyak 27 siswa (79.41\%). Sedangkan 2 siswa (5.88\%) menyatakan kadang-kadang. Sedangkan sisanya 5 (14.71\%) menyatakan tidak pernah.

2. Sebanyak 30 siswa (88.24\%) menyatakan kesulitan berbicara bahasa Inggris. Sedangkan sisanya 4 siswa $(11.76 \%)$ menyatakan biasa.

3. Siswa yang mengalami kesulitan berbicara bahasa Inggris dalam bidang ucapan 30 siswa (88.24\%), kosa kata 29 siswa (85.29\%), dan tata bahasa 28 siswa $(82.35 \%)$.

4. Sebanyak 30 atau siswa $(88.24 \%)$ menyatakan bahwa cara mengajar guru biasa saja. Sedangkan sisanya atau $11.76 \%$ menyatakan tidak tahu.

5. Sebanyak 4 siswa $(11,76 \%)$ menyatakan termotivasi untuk berbicara bahasa Inggris. Sedangkan sisanya atau $88.24 \%$ menyatakan tidak termotivasi.

6. Sebanyak 34 siswa atau $100 \%$ menyatakan ingin bisa berbicara bahasa Inggris

Berdasarkan uraian di atas, maka perlu adanya penelitian yang berkaitan dengan peningkatan keberanian berbicara dan peningkatan hasil belajar berbicara siswa melalui penggunaan MENYAN dalam pembelajaran. Tujuan utama PTK ini adalah untuk mengetahui peningkatan keberanian berbicara dan hasil belajar berbicara siswa melalui penggunaan MENYAN.

Rancangan kegiatan pembelajaran dengan MENYAN dapat dilihat pada bagian alur di bawah ini. 


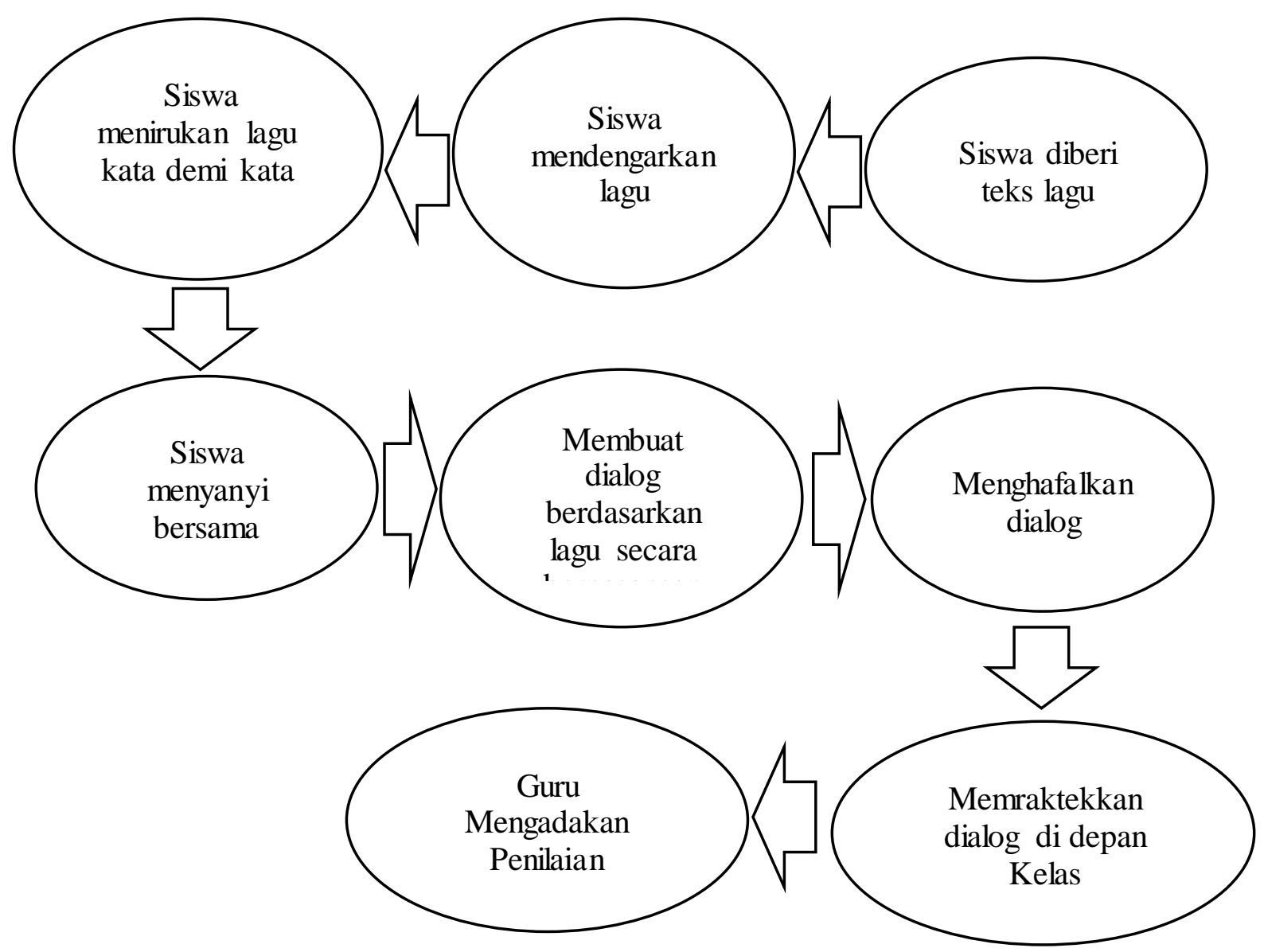

Gambar 1. Alur penggunaan MENYAN

Seperti yang dipaparkan pada alur di bagian rancangan karya inovasi di atas, pembelajaran dilaksanakan dengan menggunakan MENYAN. Setelah dilakukan telaah dan kajian pada Kompetensi Dasar 4.1 pada silabus Kurikulum 2013 (Kemendikbud: 2017) tentang menyusun teks lisan sederhana untuk mengucapkan dan merespon sapaan, pamitan, ucapan terimakasih, dan permintaan maaf, dengan memperhatikan fungsi sosial, struktur teks, dan unsur kebahasaan yang benar dan sesuai konteks.

Selanjutnya penulis memilih lagu yang cocok dengan Kompetensi Dasar 4.1 tentang fungsi social memperkenalkan diri, yaitu $A B C$ song, dengan langkah-langkah sebagai berikut. 


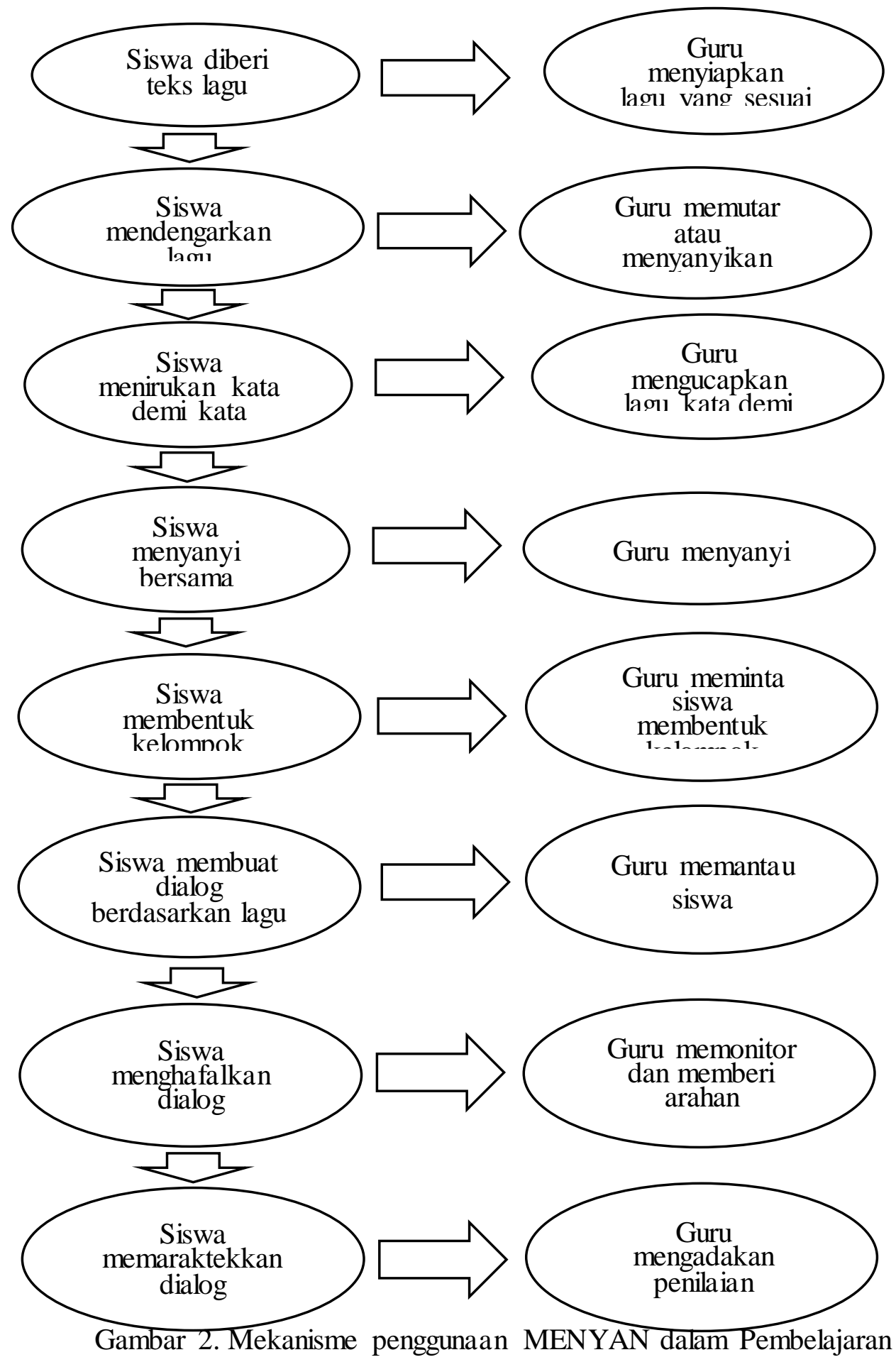

Tahapan-tahapan di proses penemuan tersebut merupakan siklus. Satu siklus adalah satu putaran yang di dalamnya meliputi tahapan perencanaan startegi pembembelajaran, tahapan pelaksanaan pembelajaran sesuai dengan strategi yang disiapkan, yang diamati tingkat keberhasilannya, dan evaluasi apakah tingkat keberhasilan sudah sesuai dengan target yang diharapkan (Latif:2010). Penulis 
merencanakan dua siklus, pada siklus pertama menggunakan MENYAN "ABC" dengan materi "what is your name?", sedangkan pada siklus kedua mengggunakan MENYAN "Family Member" dengan materi "Family Life".

Pada tahap awal pertemuan pada pembelajaran bahasa Inggris setelah guru memberi salam, berdoa, lalu mengabsen siswa, guru memberikan pertanyaan pemanasan untuk memancing siswa agar lebih fokus terhadap materi yang akan disampaikan. Disamping itu juga guru juga menyampaiakan tujuan akhir dari pertemuan tersebut. Selanjutnya pada kegiatan inti akan difokuskan pada pembelajaran yang menggunakan MENYAN.

Proses yang terjadi dalam penemuan dan pembaharuan tersebut adalah sebagai berikut.

1. Mencari lagu

Guru akan memerlukan lagu yang sesuai dengan tema yang akan diajarkan dalam hal ini $A B C$ dan Family Member Songs.

2. Pengetikan

Pada Siklus pertama menggunakan MENYAN $A B C$ dengan diketik semuanya sama persis dengan lagu aslinya, seperti berikut ini.

"ABC"
A B C D E F G H I K L M N O P
Q R S U V W X Y and Z
Now you can sing my ABC The letter of alphabet
A B C D E F G H I K L M N O P
Q R S U V W X Y AND Z
Now you can sing my ABC Tell me what you think of me

Sedangkan pada siklus kedua menggunakan MENYAN Family Member dengan ada beberapa kata yang dihilangkan, seperti berikut ini.

FAMILY MEMBERS

You should better know ................ (1)

My dad is ............ (2) F-A-T-H-E-R, F-A-T-H-E-R

$\mathrm{My} \ldots . . . . . .(3)$ is mother, M-O-T-H-E-R

This boy is my ........ (4) S-O-N Remember S-O-N Remember

This ...... (5) my daughter, D-A-U-G-H-T-E-R

This man is my ........ (6) This woman is my

This woman is my ....... (8) The old man's

The old woman's

Can you remember, who is father? Who is mother? 


\section{Penggandaan}

Selanjutnya pada penggandaan, digandakan sejumlah siswa

\section{Memutar Lagu}

Pada tahapan ini perlu dipersiapkan LCD atau TV untuk memutar lagu, dan audio yang cukup agar suara terdengar dengan jelas oleh siswa.

Penggunaan MENYANini dilaksanakan pada pembelajaran pada KD 4.1 tentang keterampilan berbicara tentang menanyakan nama teman dan menceritakan keluarganya sendiri di depan kelas. Artinya kegiatan ini bertujuan akhir untuk meningkatkan keterampilan berbicara.

\section{METODE}

Penelitian ini merupakan penelitian tindakan kelas (PTK) yang bertujuan untuk memecahkan masalah-masalah pembelajaran. Subjek penelitian ini adalah siswa kelas VIIA SMPN 2 Genteng kabupaten Banyuwangi tahun pembelajaran 2016/2017 dengan jumlah siswa 34 .

Instrumen yang digunakan dalam PTK ini adalah tes dan lember observasi dalam pembelajaran.

PTK ini dilaksanakan dalam dua siklus, setiap siklus terdari dari empat langkah yaitu perencanaan, tindakan, pengamatan, dan refleksi (Latif:2010). Pada perencanaan penelitian menyiapkan rencana pelaksanaan pembelajran (RPP), teks nyanyian yang rumpang, nyanyian, dan alat pemutar nyanyian, tes hasil belajar, dan instrument observasi. Pada tindakan yang dilakukan adalah melaksanakan RPP yang sudah dibuat dengan menggunakan MENYAN.

Langkah observasi digunakan untuk mengumpulkan data perubahan kinerja pembelajaran. Dan yang terakhir adalah refleksi yang digunakan untuk mencermati, mengevaluasi keseluruhan informasi yang dikumpulkan dalam langkah observasi. Dengan refleksi ini peneliti mengetahui plus minusnya pada saat pembelajaran, sehingga peneliti dapat memperbaiki kekurangan pada siklus berikutnya. Model PTK tiap-tiap siklus dapat digambarkan sebagai berikut: 


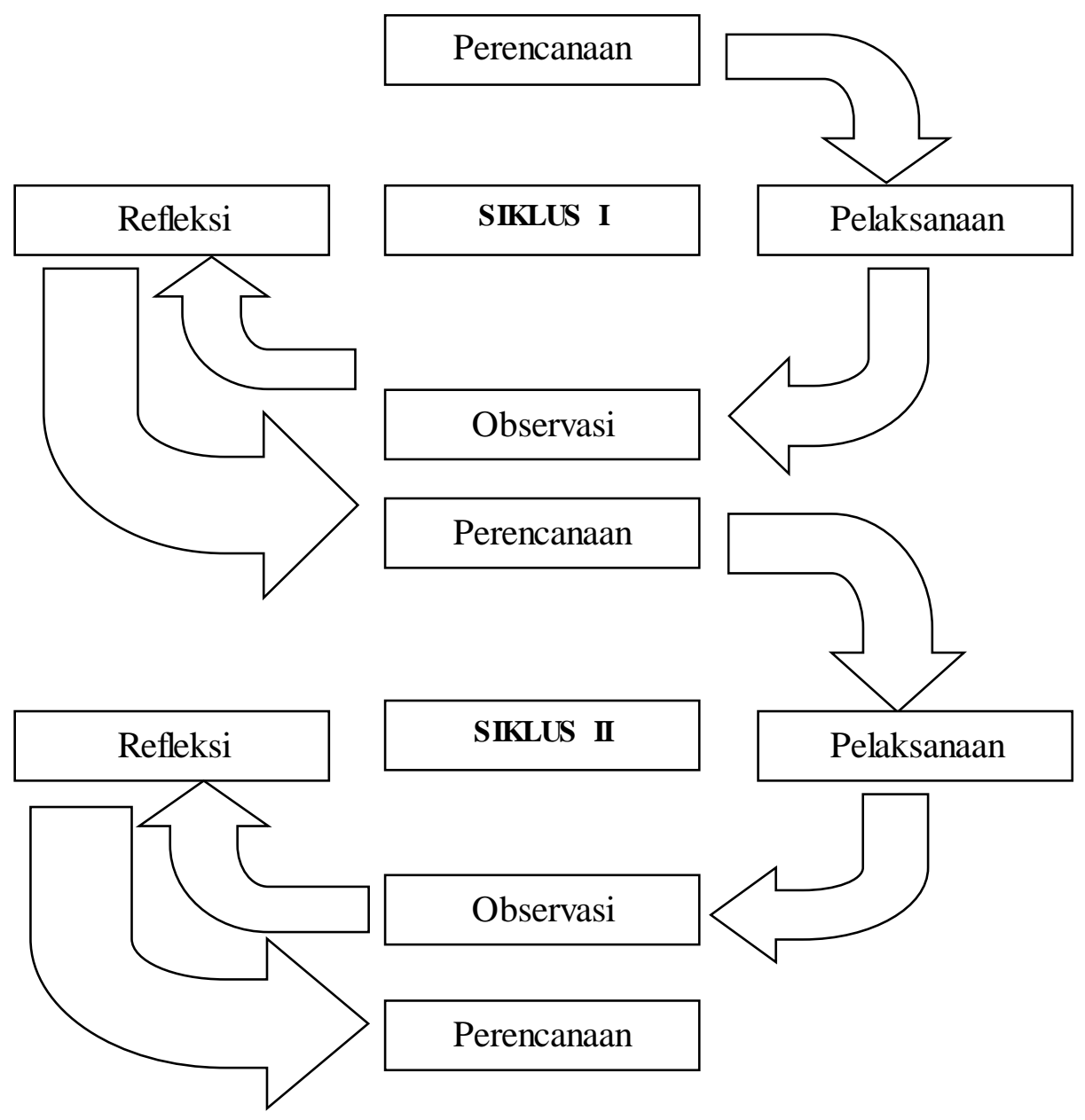

Gambar 3.

Siklus Penelitian Tindakan Kelas

Indikator keberhasilan dalam PTK ini yaitu jumlah siswa yang mencapai penguasaan belajar mengalami peningkatan apabila memperoleh nilai minimal $75 \%$ dari nilai ideal dan menguasai secara kelas bila jumlah siswa yang telah menguasai belajar minimal 75\% (ketuntasan belajar minimal SMPN 2 Genteng).

\section{PEMBAHASAN}

Setelah peneliti memperoleh gambaran umum atau kondisi awal siswa kelas VIIA, maka peneliti melakukan kegiatan pembelajaran seperti yang direncanakan dalam rencana pembelajaran. Berikut disajikan hasil siklus I dan siklus II.

\section{Pada Siklus I}

a. Semua siswa atau 34 siswa mau mendengarkan lagu yang diputar oleh guru walaupun diulang-ulang sampai 3 kali.

b. Dalam menirukan lagu kata demi kata terdapat $91.18 \%$ dapat menirukan, sisanya atau $8.82 \%$ diam saja.

c. Dalam hal menyanyi bersama semua siswa atau $100 \%$ terlibat. 
d. Dalam hal membuat dialog sederhana berdasarkan nyanyian terdapat $97.06 \%$ siswa membuat walaupun masih ada 50\% masih salah struktur sedangkan sisanya tidak membuat.

e. Dalam hal memraktekkan dialog di depan kelas tedapat 17 siswa atau $50 \%$ berani walaupun masih terdapat salah ucap. 15 siswa atau $44.12 \%$ malu-malu dan sisanya 2 atau $5.88 \%$ tidak berani.

\section{Pada Siklus II}

a. Semua siswa atau 34 siswa (100\%) mau mendengarkan lagu yang diputar oleh guru meskipun diulang sampai 3 kali atau 4 kali.

b. Dalam menirukan lagu kata demi kata terdapat $94.12 \%$ dapat menirukan sisanya atau $5.88 \%$ masih ragu-ragu.

c. Dalam menyanyi bersama semua siswa atau $100 \%$ terlibat.

d. Dalam hal membuat dialog atau presentasi sederhana berdasarkan nyanyian, semua siswa membuat walaupun masih ada $44.12 \%$ masih salah struktur.

e. Dalam hal mempraktekkan dialog atau presentasi di depan kelas terdapat 25 siswa atau $73.53 \%$ berani. 8 siswa atau $23.53 \%$ malu-malu dan sisanya 1 siswa atau $2.94 \%$ tidak berani.

\section{Hasil Angket}

Langkah selanjutnya peneliti membagikan angket yang dimaksudkan untuk mengetahui sejauh mana prilaku siswa terhadap kegiatan pembelajaran yang disajikan oleh guru. Berikut ini adalah hasil rekapitulasi hasil angket siswa tentang pasca pembelajaran berbicara bahasa Inggris dengan menggunakan MENYANmulai siklus I sampai dengan siklus II adalah sebagai berikut: 
Tabel 1.

Hasil Angket siklus I dan siklus II

\begin{tabular}{|c|c|c|c|}
\hline No & Aspek yang ditanyakan & S-I & S- \\
\hline 1. & $\begin{array}{l}\text { Siswa yang memanfaatkan } \\
\text { berbicara melalui nyanyian }\end{array}$ & 34 & 34 \\
\hline 2. & $\begin{array}{l}\text { Siswa yang merasakan senang dan semangat mengik uti } \\
\text { pembelajran melalui lagu }\end{array}$ & 34 & 34 \\
\hline \multirow[t]{4}{*}{3.} & $\begin{array}{l}\text { Siswa yang merasakan kesulitan } \\
\text { pembelajaran melalui lagu dalam hal : }\end{array}$ & & \\
\hline & Pendengaran & 33 & 30 \\
\hline & Ucapan & 30 & 25 \\
\hline & - Arti & 25 & 15 \\
\hline \multirow[t]{5}{*}{4.} & Cara siswa mengatasi kesulitan & & \\
\hline & Bertanya pada guru & 20 & 17 \\
\hline & - Bertanya pada teman & 10 & 6 \\
\hline & Buka kamus & 30 & 25 \\
\hline & Diam saja & 5 & 2 \\
\hline 5. & $\begin{array}{l}\text { Perasaan siswa terhadap teknik pembelajaran melalui } \\
\text { nyanyian semuanya merasakan senang }\end{array}$ & 34 & 34 \\
\hline 6. & $\begin{array}{l}\text { Siswa yang merasa terbantu oleh guru dalam berbicara } \\
\text { bahasa Inggris }\end{array}$ & 34 & 34 \\
\hline \multirow[t]{4}{*}{7.} & $\begin{array}{l}\text { Siswa yang menyatakan termotivasi terhadap masalah } \\
\text { pembelajaran melalui lagu }\end{array}$ & & \\
\hline & $>\mathrm{Ya}$ & 30 & 34 \\
\hline & Biasa & 4 & 0 \\
\hline & $>$ Tidak & 0 & 0 \\
\hline \multirow[t]{4}{*}{8.} & Bantuan guru yang menyenangkan dan bersifat ramah. & & \\
\hline & $\bullet \mathrm{Ya}$ & 17 & 25 \\
\hline & Biasa saja & 15 & 8 \\
\hline & Tidak & 2 & 1 \\
\hline \multirow[t]{4}{*}{9.} & $\begin{array}{l}\text { Yang dirasakan siswa pada waktu berbicara bahasa } \\
\text { Inggris di depan kelas }\end{array}$ & & \\
\hline & Tidak takut & 17 & 25 \\
\hline & - Takut sedikit & 10 & 10 \\
\hline & Tidak berani & 10 & 5 \\
\hline 10 & $\begin{array}{l}\text { Siswa yang berani berbicara bahasa Inggris dengan guru } \\
\text { bahasa Inggris diluar kelas / luar jam pelajaran }\end{array}$ & 2 & 5 \\
\hline \multirow[t]{7}{*}{11} & $\begin{array}{l}\text { Teknik pembelajaran bahasa Inggris yang disukai siswa } \\
\text { mulalui : }\end{array}$ & & \\
\hline & Nyanyian & 33 & 34 \\
\hline & Tanya jawab & & \\
\hline & Penterjemahan & 9 & 8 \\
\hline & Ceramah & & \\
\hline & • Diskusi & & \\
\hline & Penugasan & & \\
\hline
\end{tabular}


Dari hasil angket pasca pembelajaran yang menggunakan MENYAN dalam pembelajaran semua siswa merasakan senang, semua siswa memanfaatkannya, merasa terbantu, dan terjadi peningkatan dalam hal keberanian berbicara dari 17 siswa menjadi 25 siswa.

\section{Hasil Observasi}

Pada saat peneliti melaksanakan kegiatan pembelajaran melalui media nyanyian, maka teman sejawat peneliti melakukan kegiatan observasi di kelas peneliti. Berikut ini adalah beberapa hal yang perlu disampaikan dalam kegiatan ini:

\section{a. Hasil Observasi Siswa}

Hasil observasi siswa mulai siklus I sampai siklus II adalah sebagai berikut:

Tabel 2.

Hasil Observasi Siswa Siklus I dan Siklus II

\begin{tabular}{|l|l|c|c|}
\hline No & \multicolumn{1}{|c|}{ Aspek yang ditanyakan } & Siklus I & Siklus II \\
\hline 1. & Mengajukan pertanyaan kepada guru & 20 & 10 \\
\hline 2. & Menanggapi respon siswa lain & 10 & 25 \\
\hline 3. & Menjawab pertanyaan guru & 32 & 34 \\
\hline 4. & Belajar dengan media & 34 & 34 \\
\hline 5. & Dikelas gaduh dan ramai & Ya & Ya \\
\hline 6. & Mengerjakan tugas dengan baik & 5 & 10 \\
\hline 7 & Mengalami stress dan bingung & 3 & 1 \\
\hline 8. & Mengalami kesenangan & 34 & 34 \\
\hline 9. & Mengalami keaktifan & 33 & 34 \\
\hline 10. & Mengalami kepasifan & 1 & 0 \\
\hline 11. & Siswa "Off task" & 1 & 0 \\
\hline
\end{tabular}

Dari hasil table observasi siswa diatas terlihat semua siswa belajar dan mengalami kesenengan belajar dengan media nyanyian.

\section{b. Hasil Observasi Guru}

Hasil obervasi guru terlihat pada siklus I sampai dengan siklus II terlihat sebagai berikut:

Tabel 3. Hasil Observasi Guru Siklus 1 dan Siklus 2

\begin{tabular}{|c|l|c|c|}
\hline No & \multicolumn{1}{|c|}{ Aspek yang diamati } & $\begin{array}{c}\text { Siklus } \\
\text { I }\end{array}$ & $\begin{array}{c}\text { Siklus } \\
\text { II }\end{array}$ \\
\hline 1 & Melakukan pre activity & Tidak & Ya \\
\hline 2 & Meragakan kegiatan berbicara & Ya & Ya \\
\hline 3 & Menjelaskan materi nyanyian & Ya & Ya \\
\hline 4 & Menggunakan media pembelajaran & Ya & Ya \\
\hline
\end{tabular}




\begin{tabular}{|c|l|c|c|}
\hline 5 & Meberikan contoh & Ya & Ya \\
\hline 6 & $\begin{array}{l}\text { Mengajukan pertanyaan kepada } \\
\text { siswa }\end{array}$ & Ya & Ya \\
\hline 7 & Menjawab pertanyaan siswa & Ya & Ya \\
\hline 8 & Menegur siswa yang "of task" & Tidak & Ya \\
\hline 9 & Memberikan ulasan jawaban siswa & Tidak & Ya \\
\hline 10. & $\begin{array}{l}\text { Memberikan tugas kepada siswa dan } \\
\text { kelas }\end{array}$ & Ya & Ya \\
\hline 11. & Memantau kegiatan siswa & Ya & Ya \\
\hline 12. & Memberikan bantuan kepada siswa & Ya & Ya \\
\hline 13. & Berlaku adil kepada siswa & Tidak & Ya \\
\hline
\end{tabular}

Dari hasil observasi guru di atas terlihat pada siklus II perubahan atau peningkatan dalam hal melakukan pre-activity, menegur siswa yang "off task", memberi ulasan, dan berlaku adil kepada siswa.

\section{c. Hasil Obsevasi Kelas}

Untuk Hasil observasi kelas terlihat secara lengkap mulai siklus I sampai siklus II untuk hasil observasi kelas adalah sebagai berikut:

Tabel 4. Hasil Observasi Kelas Siklus I dan II

\begin{tabular}{|c|l|c|c|}
\hline No & Aspek yang diamati & Siklus I & Siklus II \\
\hline 1. & $\begin{array}{l}\text { Persiapan ( AMP, Promes, Jurnal, RP, } \\
\text { Evaluasi) }\end{array}$ & Ada & Ada \\
\hline 2. & Pemberian motivasi kepada siswa & Ada & Ada \\
\hline 3. & Bahasa pengantar bahasa Inggris & Ada & Ada \\
\hline 4. & Teknik bertanya & Tidak ada & Tidak ada \\
\hline 5. & Pengelompokan siswa & Ada & Ada \\
\hline 6. & Monitoring & Ada & Ada \\
\hline 7. & Penggunaan alat bantu pembelajaran & Ada & Ada \\
\hline 8. & Prosedur pengajaran & Ada & Ada \\
\hline 9. & $\begin{array}{l}\text { Interaksi : guru-siswa, siswa-guru, } \\
\text { siswa-siswa }\end{array}$ & Ada & Ada \\
\hline 10. & Persiapan dan aktivitas siswa & Ada & Ada \\
\hline 11. & Penanganan kesulitan siswa & Ada & Ada \\
\hline 12. & Penggunaan bahasa Inggris siswa & Ada & Ada \\
\hline 13. & Rasa percaya diri siswa & Ada & Ada \\
\hline 14. & Kejelasan suara guru & Cukup & Baik \\
\hline 15. & Penampilan guru & Cukup & Baik \\
\hline
\end{tabular}

Dari Hasil observasi kelas di atas terdapat perubahan/peningkatan dalam hal kejelasan suara dan penampilan guru di dalam pembelajaran

\section{Hasil Nilai Ulangan}

SMP Negeri 2 Genteng Kabupaten Banyuwangi menerapkan Ketuntasan Belajar Minimal (KBM) 75. Siswa dikatakan tuntas belajar apabila nilai yang 
diperoleh $>=75$. Hasil ulangan harian siswa kelas VIIA dari kondisi awal sampai dengan siklus II adalah sebagai berikut.

Tabel 5. Nilai Keterampilan pada siklus I dan Siklus II

\begin{tabular}{|c|l|c|c|c|}
\hline \multirow{2}{*}{ No } & \multirow{2}{*}{ Nama Siswa } & \multicolumn{3}{|c|}{ Nilai Speaking } \\
\cline { 2 - 5 } & & Pretest & Siklus 1 & Siklus \\
\hline 1 & Achmad Reizal Rama Ade Putra & 70 & $\mathbf{7 5}$ & 70 \\
\hline 2 & Agelia Kharisma Putri & $\mathbf{7 5}$ & $\mathbf{7 5}$ & $\mathbf{7 5}$ \\
\hline 3 & Ajeng Puspitasari & $\mathbf{8 0}$ & $\mathbf{8 2}$ & $\mathbf{8 0}$ \\
\hline 4 & Astri Aulia & 60 & $\mathbf{7 7}$ & $\mathbf{7 8}$ \\
\hline 5 & Ayu Amelia Anwar & 65 & $\mathbf{7 6}$ & $\mathbf{7 9}$ \\
\hline 6 & Bagus Saputro & 60 & 62 & 60 \\
\hline 7 & Bebi Natalia & 55 & 55 & 55 \\
\hline 8 & Bilqish Nur Azizah & 50 & $\mathbf{7 5}$ & $\mathbf{8 0}$ \\
\hline 9 & Bima Gafara Elfanda & 45 & 50 & $\mathbf{7 5}$ \\
\hline 10 & Calvin Ferrys Brendyano & $\mathbf{7 5}$ & $\mathbf{7 5}$ & $\mathbf{7 5}$ \\
\hline 11 & Dwi Rini Wijayanti & 70 & 70 & $\mathbf{7 6}$ \\
\hline 12 & Galuh Tri Lestari & $\mathbf{7 8}$ & $\mathbf{7 9}$ & $\mathbf{8 1}$ \\
\hline 13 & Gebby Veralia Sandra & $\mathbf{7 8}$ & $\mathbf{7 8}$ & $\mathbf{8 2}$ \\
\hline 14 & Hadi Setyo Prayogo & 66 & 60 & $\mathbf{7 5}$ \\
\hline 15 & Ika Yanuar Susiana & 67 & 60 & 70 \\
\hline 16 & Larisa Ribka Lestari & 68 & 68 & $\mathbf{7 6}$ \\
\hline 17 & Moh. Fajril Zidan An Im M. & 72 & $\mathbf{7 6}$ & $\mathbf{7 7}$ \\
\hline 18 & Mohammad Alva Miftahul H. & $\mathbf{7 5}$ & $\mathbf{7 5}$ & $\mathbf{7 6}$ \\
\hline 19 & Nanda Rizki Srihendriawan & $\mathbf{7 6}$ & $\mathbf{7 6}$ & $\mathbf{7 6}$ \\
\hline 20 & Neninda Failza & 66 & 70 & $\mathbf{7 7}$ \\
\hline 21 & Ni Kadek Novia Putri M & 46 & 50 & 56 \\
\hline 22 & Nurul Aini & 60 & 65 & $\mathbf{7 5}$ \\
\hline 23 & Ramadhan Diaz Syaputra & 60 & 60 & 60 \\
\hline 24 & Rara Ayuning Prameswari & 67 & 67 & 67 \\
\hline 25 & Rizki Firmansyah & $\mathbf{7 7}$ & $\mathbf{7 6}$ & $\mathbf{7 8}$ \\
\hline 26 & Septian Dwi Cahyo & $\mathbf{7 6}$ & $\mathbf{7 6}$ & $\mathbf{7 6}$ \\
\hline 27 & Shellyna Octa Rahmadaniyah Z. & 55 & 55 & $\mathbf{7 5}$ \\
\hline 28 & Siti Elina Awalul Fitri & 50 & 55 & $\mathbf{7 7}$ \\
\hline 29 & Siti Nazirotul Hasanah & 55 & $\mathbf{7 5}$ & $\mathbf{8 0}$ \\
\hline 30 & Tri Puspita Sari & 57 & $\mathbf{7 6}$ & $\mathbf{7 8}$ \\
\hline 31 & Tri Wahyuni & 66 & 66 & $\mathbf{7 7}$ \\
\hline 32 & Umi Mu`Alimah & 70 & $\mathbf{7 5}$ & $\mathbf{7 9}$ \\
\hline 33 & Vivit Arista Dewi & $\mathbf{7 5}$ & $\mathbf{7 9}$ & $\mathbf{8 4}$ \\
\hline 34 & Wika Erma Desiska & $\mathbf{1 8}$ & $\mathbf{2 7}$ \\
\hline & Jumlah siswa yang tuntas atau & & \\
\hline & & & 70 & $\mathbf{7 9}$ \\
\hline
\end{tabular}

Dari table hasil belajar siswa di atas terjadi peningkatan jumlah siswa yang tuntas mengikuti pembelajaran dari pre-tes berjumlah 11, siklus I berjumlah 18, dan pada siklus II berjumlah 27 siswa. 
Berdasaran analisis diperoleh bahwa metode pembelajaran bahasa Inggris melalui media nyanyian (MENYAN) terbukti membuat siswa merasa senang dan termotivasi untuk berbicara bahasa Inggris. Hal ini terlihat pada hasil angket pasca pembelajaran pada siklus demi siklus. Siklus I ada 34 siswa atau 100\% siklus II ada 34 siswa atau $100 \%$.

Suasana dalam pembelajaran yang menggunakan MENYAN menarik perhatian, tidak membosankan, rileks dan tidak menakutkan sehingga akan lebih menambah rasa percaya diri siswa untuk berkomunikasi dalam bahasa Inggris. Hal ini terlihat pada hasil angket pasca pembelajaran siklus per siklus. Siklus I terdapat 17 atau 50\%, siklus II terdapat 25 atau $73,53 \%$. Hal ini menunjukkan ada peningkatan.

Dengan menggunakan MENYAN ternyata dapat meningkatkan nilai keterampilan berbicara siswa, dari pre-test ada 11 siswa yang tuntas, dari siklus I terdapat 18 siswa, dan pada siklus II ada 27 siswa yang nilainya >=75 (KBM).

Berikut adala grafik peningkatan keberanian berbicara siswa baik di kelas maupun di luar kelas. Juga tampak ada pada grafik peningkatan pada nilai ulangan harian siswa tentang berbicara.

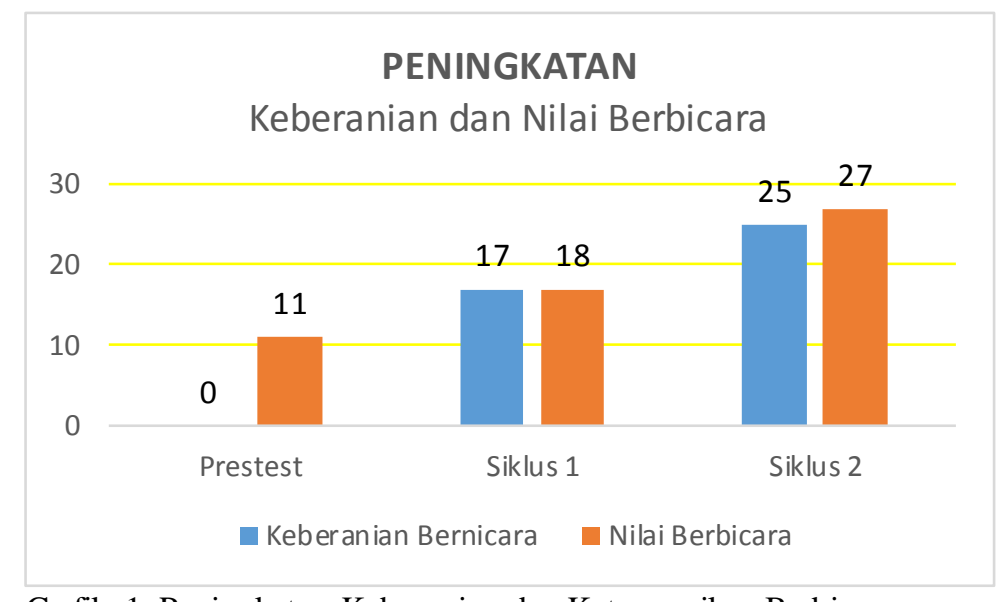

Grafik 1. Peningkatan Keberanian dan Keterampilan Berbicara

\section{KESIMPULAN}

Berdasarkan hasil penelitian dapat diambil simpulan bahwa:

1. Penggunaan media nyanyian (MENYAN) terbukti menyenangkan, membangkitkan minat, rileks, dan tidak menjemukan sehingga dapat meningkatkan keberanian berbicara siswa kelas VIIA SMPN 2 Genteng Kabupaten Banyuwangi.

2. Bahwa pembelajaran dengan menggunakan MENYAN yang penyajiannya secara menarik terbukti mampu meningkatkan nilai keterampilan berbicara siswa.

Dari hasil-hasil penelitian yang diperoleh, dapat disarankan bahwa pengguna an MENYAN dapat digunakan untuk materi-materi lain dalam pembelajaran bahasa Inggris 
agar pembelajaran tetap menarik, tidak membosankan, dan menyenangkan. Juga untuk para peneliti lain yang menggunakan MENYAN ini agar berhasil dengan baik perlu memperhatikan hal-hal berikut.

1. Dalam pemilihan lagu harus benar-benar sesuai dengan tema yang akan dibahas dan guru harus mempunyai jiwa seni yang bisa bermain gitar, keyboard atau lainnya, kalau perlu kerjasama dengan guru kesenian

2. Agar tidak mengganggu kelas lain penggunaan MENYAN ini perlu ruangan khusus yang kedap udara untuk menyanyi bersama-sama

3. Dalam berkolaborasi dengan guru bahasa Inggris lain harus terjadwal dengan baik agar tidak mengganggu tugas masing-masing

\section{DAFTAR PUSTAKA}

Azhar, Arsyad. 2010. Media Pembelajaran. Jakarta: PT Raja Grafindo Persada

Brown, H. Douglas. 2007. Teaching by Principles: An Interactive Approach to Languange Pedagogy. New York: Pearson Education.

Dorry, G.N. 1996. Gamefor Second Language Learning. New York: MacGraw Hill Book Company.

Hamdani. 2011. Strategi Belajar Mengajar. Bandung: CV Pustaka Setia

Hermina, Br. Simanora. 2017. Praktik yang Baik Pembelajaran di SMP/MTs. Jakarta: USAID PRIORITAS

https:/id.wikipedia.org/wiki/Lagu. Diakses Tgl 25 Juli 2017

Ismukoco. 2017. Tehnik Mengajar Sepaking. Surabaya: Alpha

Jauhar, Mohamad. 2011. Implementasi PAIKEM dari Behavioristik sampai Konstruktivistik. Jakarta: Prestasi Pustakaraya

Kementerian Pendidikan dan Kebudayaan.2017. Panduan Pembelajaran untuk Sekolah Menengah Pertama. Kementerian Pendidikan dan Kebudayaan, Jakarta.

Latif, Mohammad Adnan. 2010. Tanya Jawab Metode Penelitian Pembelajaran Bahasa. Malang: Universitas Negeri Malang (UM Press).

Peorwadarminta, W.J.S. 2011. Kamus Umum Bahasa Indonesia. Jakarta: Balai Pustaka

Sadiman, Arif S. 2007. Media Pendidikan: Pengertian, Pengembangan dan Pemanfaatannya. Jakarta: PT Raja Grafindo Persada.

SMPN 2 Genteng. 2015. Kurikulum Tingkat Satuan Pendidikan.Dinas Pendidikan SMPN 2 Genteng, Banyuwangi. 